\title{
Bioaerosols from mouth-breathing: Under-recognized transmissible mode in COVID-19?
}

\author{
Saravanakarthikeyan Balasubramanian ${ }^{1 *}$, Divya Vinayachandran²
}

\begin{abstract}
The whole world has been affected by the coronavirus disease 2019 (COVID-19) pandemic, and many researchers are racing to understand the disease course and to undertake risk analyses to formulate effective treatment strategies. Severe acute respiratory syndrome coronavirus 2 (SARS-CoV-2) is highly transmissible through coughing and sneezing, and through breathing and talking which may account for viral transmission from asymptomatic carriers. Bioaerosols produced during mouth-breathing, an expiratory process in habitual mouth breathers, should be considered in addition to nasal bioparticles as a potential transmissible mode in COVID-19. Oral health professionals are justifiably apprehensive about the exposure risk due to close face-to-face contact and the mode of transmission. The aim of this commentary is to summarize the research conducted in this area and suggested strategies to limit the spread of COVID-19, especially in dental offices.
\end{abstract}

Suggested citation: Balasubramanian S, Vinayachandran D. Bioaerosols from mouth-breathing: Under-recognized transmissible mode in COVID-19? Can Commun Dis Rep 2021;47(5/6):276-8 https://doi.org/10.14745/ccdr.v47i56a05

Keywords: bioaerosols, coronavirus, COVID-19, mouth-breathing, oral diagnosis, transmission risk

Note from the Editor: In Canada, the prevalence of COVID-19 infection among the dental profession is very low due to the large amount of personal protective equipment available, the patient's pre-screening routine, and the amount of mandatory training on infection prevention techniques. Furthermore, it is important to clarify the concepts presented in this article. Expiratory particles apply to both droplets and bioaerosols. The difference between droplets and bioaerosols is their size, which impacts their potential "travelling" distance from infected person to the person at risk standing by or passing by. See: COVID-19: Guidance on indoor ventilation during the pandemic.

\section{Introduction}

Severe acute respiratory syndrome coronavirus 2 (SARS-CoV-2), the causative virus for coronavirus disease 2019 (COVID-19), is reported to be highly transmissible through respiratory droplets and aerosols emitted during coughing, sneezing, speaking and singing. This paper focus on aerosol-generating procedures in medical and dental fields (1). Recent reports have emphasized the possible role of SARS-CoV-2 transmission through expiratory particles emitted during normal breathing and speaking activities $(2,3)$. Biological aerosols (less than 1 $\mu \mathrm{m}$ in size) are also produced in large quantities during mouthbreathing and the impact of mouth-breathing should also be considered in SARS-CoV-2 transmission (4). This is highly relevant in a dental office where the patients must open their mouths for a considerable time, posing a threat of disease transmission risk through expiratory bioparticles. There are currently no research reports or reviews on this transmission route. Hence, our commentary presents an overview of mouth-breathing and its potential significance in SARS-CoV-2 transmission, especially in a dental practice. This issue affects all dental professionals, including dentists, oral hygienists and dental assistants. In addition, we highlight few research questions pertaining to the mouth-breathing expiratory particles that need urgent answers through appropriate research to effectively control transmission of SARS-CoV-2 in a clinical setting. 


\section{Exhaled bioparticles and potential routes of infection in a dental office}

Generally, the potential routes of infection for communicable diseases in a dental office include direct contact with body fluids (saliva/blood) of an infected patient, contact with the instruments/environmental surfaces contaminated by patients and through infectious aerosol particles (5). In the particular case of COVID-19 disease, the exhaled bioparticles can be emitted from patients through various respiratory actions, including mouth-breathing, nose breathing, coughing and talking. Pappineni and Rosenthal (6) investigated the exhaled droplets through these various modes using an optical particle counter and an analytical transmission electron microscope. The investigators reported that the quantity of droplets emitted was highest in coughing, followed by mouth-breathing, nasal breathing and talking, respectively. The smaller number of bioparticles emitted through nasal breathing when compared with mouth-breathing may be attributed to the filtration processes that occur in the nasal cavity (6). These expiratory bioaerosol droplets are polydispersed and the droplet size has a huge impact on the disease transmission process $(2,4,6)$. Smaller droplets evaporate quickly and become "droplet nuclei" that can remain airborne for extended periods (7). These smaller aerosol particles $(0.5-10 \mu \mathrm{m}$ in diameter) can penetrate and lodge in the tiny lung passages and provoke high infection risk (8).

\section{Mouth-breathing: An overlooked risk factor in COVID-19?}

Alarmingly, COVID-19 is also highly transmissible in the pre-symptomatic/non-symptomatic carriers $(9,10)$. Mouth-breathing, which is characterized by inhalation and exhalation through the mouth resulting mainly from upper airway obstruction or when it becomes a chronic behavioural pattern, it is categorized as an abnormal respiratory function. Mouth breathers are those persons with half-open, dry and cracked lips, an anteriorized tongue, weak mandibular elevator muscles, a deep and narrow palate, dental alterations and predominantly vertical face growth (11).

The most commonly reported causes of mouth-breathing included chronic allergic rhinitis (81.4\%), adenoid hypertrophy (79.2\%), enlarged tonsils (12.6\%) and deviated nasal septum (1.0\%) (12,13). Major clinical manifestations of mouth-breathers were sleeping with open mouth (86\%), snoring (79\%), itchy nose (77\%), saliva drooling (62\%), nocturnal sleep problems (62\%), nasal obstruction (49\%) and general irritability (43\%) (13). Further, many dental problems, including dental caries, periodontal diseases, halitosis, craniofacial deformity and malocclusion, are commonly observed in mouth breathers (12-14).
Recently, it has been reported that nasal nitric oxide may help to reduce SARS-CoV-2 viral load and the risk of COVID-19 pneumonia by promoting more efficient antiviral defense mechanisms in the respiratory tract (15). However, mouthbreathing significantly reduces the effectiveness of nitric oxide, reducing the antiviral response (in contrast to nasal breathing). This observation highlights the importance of mouth-breathing expiratory bioparticles in COVID-19 transmission, and the importance of differentiating between the mouth and the nose as transmission routes of bioaerosols (15).

Dentists and other oral health professionals in a dental office are at high risk of exposure to these asymptomatic individualsboth those who are chronic mouth-breathers and those who must keep their mouth open for a considerable time during routine dental examination. Since it is well known that these emitted particles can facilitate the spread of various infectious diseases, including influenza (16), it is a concern that they might also facilitate the spread of COVID-19. Since the communicable profile of SARS-CoV-2 may more closely resemble that of influenza than of severe acute respiratory syndrome (SARS), the threat imposed due to aerosols produced from mouth-breathing (in addition to nasal breathing) should be considered (9). Both SARS-CoV-2 and influenza are characterized by increased infectiousness shortly around or even before symptom onset in contrast to that of SARS, wherein, infectiousness peaked around 7-10 days after symptom onset. Hence, the transmission of SARS-CoV-2 through expiratory bioparticles of pre-symptomatic individuals play a significant role (9). However, a careful literature review revealed that no study has considered bioaerosols produced during mouth-breathing as a potential transmissible mode for SARS-CoV-2, despite its high plausibility. Hence, this commentary aims to encourage research on 1) the potential of transmission of SARS-CoV-2 via bioaerosols and 2) methods to limit transmission, especially in a dental office.

\section{Urgent questions that need immediate attention}

Many important questions about the transmission of SARSCoV-2 via mouth-breathing need to be answered by aerosol scientists (2). Do infected but asymptomatic mouth-breathing individuals emit more bioaerosols than healthy mouth breathers? Are mouth-breathing bioaerosols better able to transmit SARS-CoV-2 than normal expiratory bioaerosols? Is rapid saliva sampling for SARS-CoV-2 a useful tool for assessing the infectivity of bioaerosols emitted in healthy/pre-symptomatic/ asymptomatic mouth breathers? What are the optimal experimental methods for assessing the virulence of biological aerosols? Summary of these issues are highlighted in Box 1. 


\section{Box 1: Highlights}

- $\quad$ SARS-CoV-2 spreads through expiratory particles emitted during normal breathing, talking, singing, shouting, coughing and sneezing

- Bioaerosols are produced in larger quantities during mouthbreathing vs normal breathing

- Mouth-breathing aerosols present as an overlooked and underestimated risk factor in COVID-19 transmission

- $\quad F u r t h e r$, more evidence is needed on COVID-19 spread through expiratory bioparticles to inform preventive measures and help combat the pandemic

\section{Conclusion}

To conclude, bioaerosols from mouth-breathing, in addition to the nasal expiratory particles, should also be considered as a potential source of transmission in COVID-19. However, concrete clinical research evidence highlighting the role of mouth-breathing bioparticles in COVID-19 transmission is mandatory to support our hypothesis, though it may sound logically true. Further, with an enormous increase in COVID-19 cases day by day, much more awareness is required amongst the oral health professionals about the disease transmission process and associated risk factors with normal expiratory activities, as mentioned by Anderson et al. (3).

\section{Authors' statement}

SKB - Conceptualization, writing-preparation of original draft DV - Conceptualization, writing-review and editing

The content and view expressed in this article are those of the authors and do not necessarily reflect those of the Government of Canada.

\section{Competing interests}

None.

\section{Funding}

None.

\section{References}

1. World Health Organization. Coronavirus disease (COVID-19): How is it transmitted? Geneva, Switzerland: WHO; 2020 (accessed 2021-03-23). https://www.who.int/emergencies/diseases/ novel-coronavirus-2019/question-and-answers-hub/q-a-detail/ coronavirus-disease-covid-19-how-is-it-transmitted
2. Asadi S, Bouvier N, Wexler AS, Ristenpart WD. The coronavirus pandemic and aerosols: does COVID-19 transmit via expiratory particles? Aerosol Sci Technol 2020;54(6):635-8. DOI PubMed

3. Anderson EL, Turnham P, Griffin JR, Clarke CC. Consideration of the Aerosol Transmission for COVID-19 and Public Health. Risk Anal 2020;40(5):902-7. DOI PubMed

4. Edwards DA, Man JC, Brand P, Katstra JP, Sommerer K, Stone HA, Nardell E, Scheuch G. Inhaling to mitigate exhaled bioaerosols. Proc Natl Acad Sci USA 2004;101(50):17383-8. DOI PubMed

5. Garner JS; The Hospital Infection Control Practices Advisory Committee. Guideline for isolation precautions in hospitals. Infect Control Hosp Epidemiol 1996;17(1):53-80.

DOI PubMed

6. Papineni RS, Rosenthal FS. The size distribution of droplets in the exhaled breath of healthy human subjects. J Aerosol Med 1997;10(2):105-16. DOI PubMed

7. Chao CY, Wan MP, Morawska L, Johnson GR, Ristovski ZD, Hargreaves M, Mengersen K, Corbett S, Li Y, Xie X, Katoshevski D. Characterization of expiration air jets and droplet size distributions immediately at the mouth opening. J Aerosol Sci 2009;40(2):122-33. DOl PubMed

8. Micik RE, Miller RL, Mazzarella MA, Ryge G. Studies on dental aerobiology. I. Bacterial aerosols generated during dental procedures. J Dent Res 1969;48(1):49-56. DOI PubMed

9. He X, Lau EH, Wu P, Deng X, Wang J, Hao X, Lau YC, Wong JY, Guan Y, Tan X, Mo X, Chen Y, Liao B, Chen W, Hu F, Zhang Q, Zhong M, Wu Y, Zhao L, Zhang F, Cowling BJ, Li F, Leung GM. Temporal dynamics in viral shedding and transmissibility of COVID-19. Nat Med 2020;26(5):672-5. DOI PubMed

10. Bai Y, Yao L, Wei T, Tian F, Jin DY, Chen L, Wang M. Presumed Asymptomatic Carrier Transmission of COVID-19. JAMA 2020;323(14):1406-7. DOI PubMed

11. Di Francesco RC. Mouth breathing: the ent doctor's point of view. J Bras Ortodon Ortop Facial. 1999;4(21):241-7. https://pesquisa. bvsalud.org/portal/resource/pt/lil-351457

12. Leboulanger $\mathrm{N}$. [Nasal obstruction and mouth breathing: the ENT's point of view]. Orthod Fr 2013;84(2):185-90.

DOI PubMed

13. Abreu RR, Rocha RL, Lamounier JA, Guerra AF. Etiology, clinical manifestations and concurrent findings in mouthbreathing children. J Pediatr (Rio J) 2008;84(6):529-35. DOI PubMed

14. Motta LJ, Alfaya TA, Marangoni AF, Ferrari RA, Fernandes KP, Bussadori SK. Gender as risk factor for mouth breathing and other harmful oral habits in preschoolers. Braz J Oral Sci 2015;11(3):377-80. https://periodicos.sbu.unicamp.br/ojs/index. php/bjos/article/view/8641374

15. Martel J, Ko YF, Young JD, Ojcius DM. Could nasal nitric oxide help to mitigate the severity of COVID-19? Microbes Infect 2020;22(4-5):168-71. DOI PubMed

16. Franková $\mathrm{V}$, Rychterová V. Inhalatory infection of mice with influenza Ao/PR8 virus. II. Detection of the virus in the blood and extrapulmonary organs. Acta Virol 1975;19(1):35-40. PubMed 